\title{
A NEW POLYENE ANTIBIOTIC, FLAVOMYCOIN STRUCTURAL INVESTIGATIONS. I
}

\author{
Rolf Schlegel and Heinz Thrum \\ Deutsche Akademie der Wissenschaften zu Berlin, \\ Zentralinstitut für Mikrobiologie und Experimentelle Therapie, \\ Jena, DDR
}

(Received for publication March 1, 1971)

\begin{abstract}
Flavomycoin is a polyene antibiotic isolated from the mycelium of Streptomyces roseoflavus ARAI 1951 var. jenensis nov. var. JA 5068 as yellow-green crystals. It shows inhibitive activities against yeasts and fungi as well as protozoa. It is optically active, exhibits an ultraviolet spectrum without fine structure with maxima at $363 \mathrm{~nm}$ and $263 \mathrm{~nm}$. Analytical studies indicated that the molecular formula of the antibiotic is $\mathrm{C}_{41} \mathrm{H}_{68} \mathrm{O}_{10}$ and the molecular weight 721. These results were confirmed by degradation to the parent hydrocarbon and by catalytic hydrogenation. As flavomycoin is different from the related substances mycoticin and flavofungin, it must be considered as a new antibiotic.
\end{abstract}

During the course of a screening program for antifungal antibiotics a new antibiotic, named flavomycoin, was obtained from the mycelium of Streptomyces roseoflavus ARAI 1951 var. jenensis nov. var. JA 50681). Flavomycoin is active against pathogenic and nonpathogenic yeasts and fungi as well as protozoa. The antibiotic was isolated by extraction of the mycelia with organic solvents. After purification it was obtained as a yellow-green crystalline substance. Flavomycoin belongs to a new group of polyene antibiotics characterized by conjugation of the polyene chromophore with the lactone group of the macrolide ring $^{2}$. The present paper deals with the physical and chemical properties of flavomycoin and some chemical investigations on its structure.

\section{Physical and Chemical Properties of Flavomycoin}

Flavomycoin crystallizes from $80 \%$ methanol or ethanol as yellow-green needles which associate to bunches. The melting point is $161 \sim 163^{\circ} \mathrm{C}$ with decomposition. Flavomycoin is freely soluble in pyridine, glacial acetic acid, water-saturated butanol and dimethylformamide, moderately soluble in aqueous aliphatic alcohols, aqueous ethyl acetate and acetone, but insoluble in water, benzene, chloroform and petroleum ether.

The optical rotation of the antibiotic is the following: $[\alpha]_{\mathrm{D}}^{23}=-4^{\circ}(c 4$, pyridine), $[\alpha]_{\mathrm{D}}^{23}=-45^{\circ}$ (c 1, 95\% dioxane), $[\alpha]_{\mathrm{D}}^{25}=-60^{\circ}$ (c 3, dimethylformamide), $[\alpha]_{\mathrm{D}}^{27}=-53^{\circ}(c$ $1.1,95 \%$ acetone), $[\alpha]_{\mathrm{D}}^{25}=+109^{\circ}$ (c 4, acetic acid), $[\alpha]_{\mathrm{D}}^{23}=-16^{\circ}$ (c 1 , methanol).

With concentrated sulf uric acid flavomycoin affords a redviolet color. It decolorizes potassium permanganate and bromine solutions, but gives negative reactions to Tollens, Molisch, ninhydrin, ferric chloride and iodoform tests. 
Flavomycoin does not contain nitrogen, phosphorus, sulfur or halogen. The results of elementary analysis of flavomycoin were as follows: C 64.49, H 9.35, O $26.16 \%$ (difference). The determination of water according to KARL FISCHER showed that the crystalline substance contains $4 \sim 5 \%$ water. From these analytical data one can calculate the following empirical formula for flavomycoin $\mathrm{C}_{41} \mathrm{H}_{68} \mathrm{O}_{10}$. $2 \mathrm{H}_{2} \mathrm{O}$.

The ultraviolet absorption spectrum of flavomycoin in methanol shows maxima at $363 \mathrm{~nm}\left(\mathrm{E}_{1 \mathrm{~cm}}^{1 \%} 860, \lg \varepsilon 4,792\right)$, at $262 \mathrm{~nm}$ ( $\left.E_{1 \%}^{1 \%} 150, \lg \varepsilon 4,033\right)$ and a shoulder at 377

Fig. 1. Ultraviolet absorption spectrum of flavomycoin in methanol.

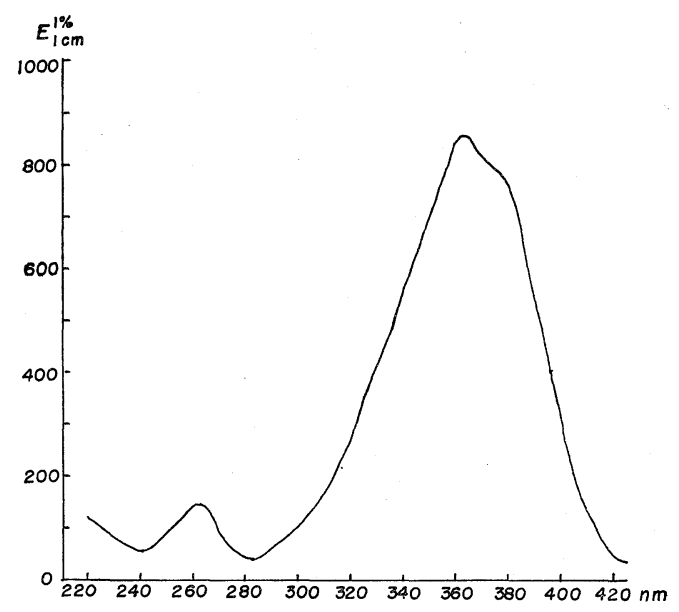

The infrared absorption spectrum in $\mathrm{KBr}$ (abtet (Fig. 2) bands at $1705 \mathrm{~cm}^{-1}$ corresponding either to a carbonyl group or an unsaturated ester and lactone group; $1585 \mathrm{~cm}^{-1}, 1630 \mathrm{~cm}^{-1}$ and $3020 \mathrm{~cm}^{-1}$ to double bonds ; $2880 \mathrm{~cm}^{-1}$ and $1940 \mathrm{~cm}^{-1}$ to methyl and methylene groups; $3400 \mathrm{~cm}^{-1}$ to hydroxyl functions. The band at $1100 \mathrm{~cm}^{-1}$ showing the highest extinction in the spectrum is attributed to a $\mathrm{C}-\mathrm{O}$ valency-vibration of an ester or lactone group.

Stability: Flavomycoin is unstable in the solid state when exposed to air and light. A crystalline sample of flavomycoin placed in an aerated petri dish during 60

Fig. 2. Infrared absorption spectrum of flavomycoin $(\mathrm{KBr})$.

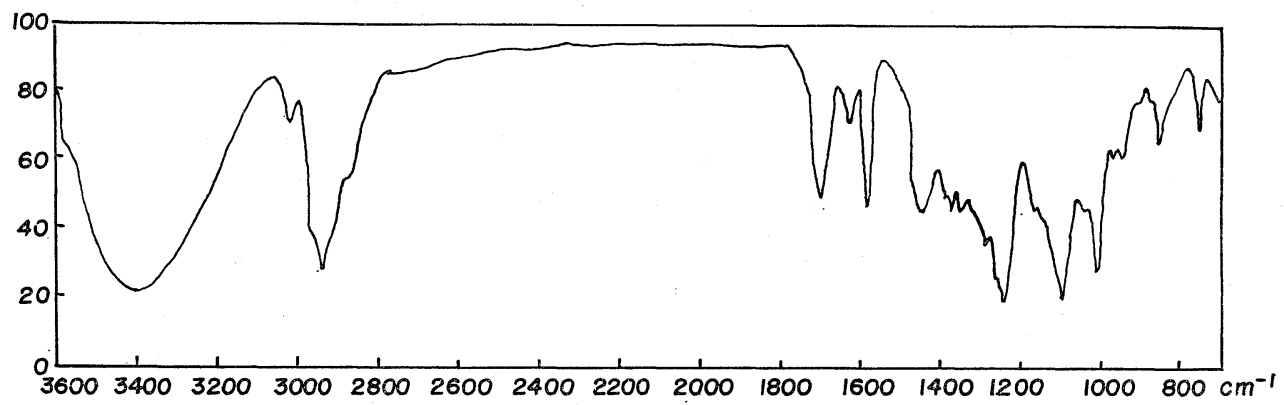

Fig. 3. Infrared absorption spectrum of perhydro-flavomycoin (KBr).

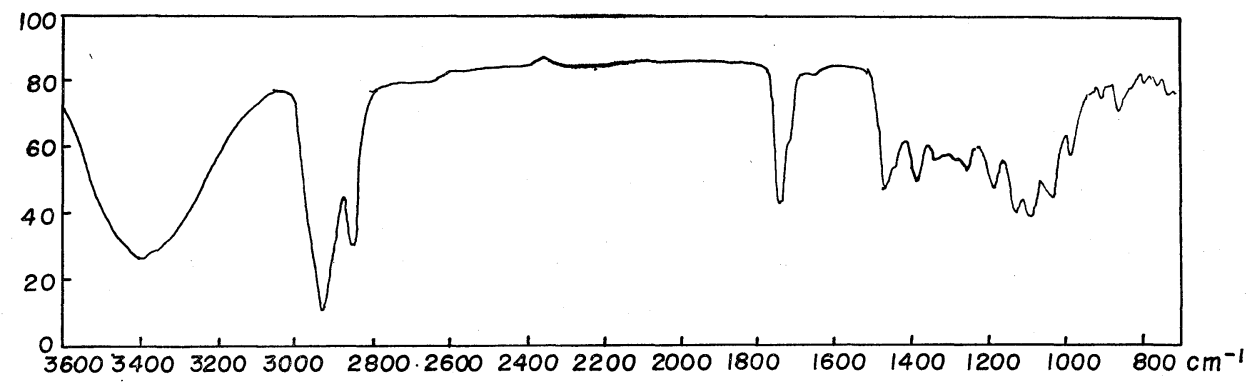


Fig. 4. Change of ultraviolet absorption of flavomycoin exposed to air.

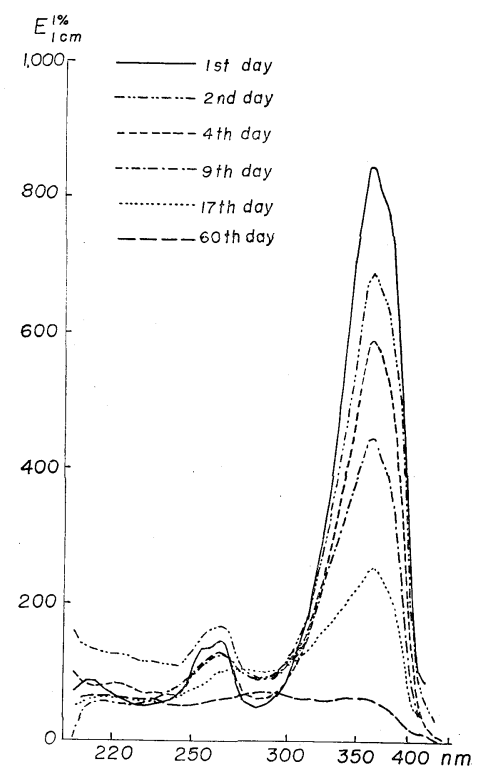

Fig. 5. Change of infrared absorption of flavomycoin exposed to air.

$\mathrm{a}=1$ st day $\mathrm{b}=4$ th day $\mathrm{c}=17$ th day $\mathrm{d}=60$ th day

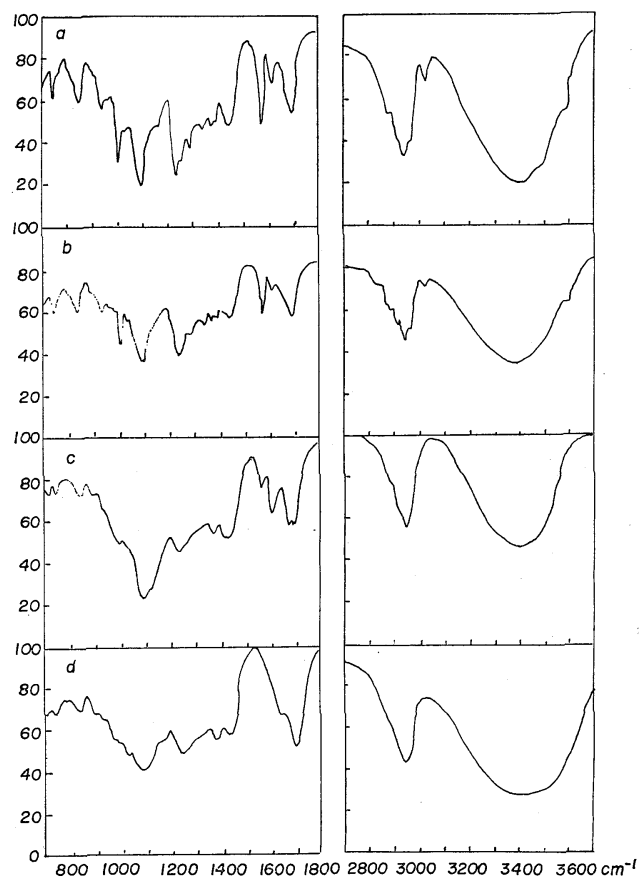

days, gave the following modifications in its ultraviolet and infrared spectra (Figs. 4 and 5). In the ultraviolet-range the maximum at $363 \mathrm{~nm}$ completely disappears, and in the infrared region the bands of the double bonds strongly decrease in intensity. The chemical destruction is accompanied by the loss of biological activity. Therefore, flavomycoin must be preserved in an inert gas atmosphere and in darkness. In aqueous solutions flavomycoin is readily destroyed at $\mathrm{pH}$-values below 6 and above 10 , but it is relatively stable in organic solvents.

\section{Determination of the Molecular Weight of Flavomycoin}

Because of the small stability and the existence of crystallization water in the molecule it was very difficult to determine the molecular weight with conventional methods. Therefore, the mass spectrometry was applied to estimate the molecular weight of flavomycoin. Fig. 6 shows the negative ion sprectrum of flavomycoin which was taken by using of low energy $(2 \sim 4 \mathrm{eV})^{3,4)}$. The highest peak at m/e 720 is identical with the molecular ion peak, while the next peaks are caused by cleavage of at least six moles $\mathrm{H}_{2} \mathrm{O}$ from the molecule $\left(720=\mathrm{M}, 702=\mathrm{M}-\mathrm{H}_{2} \mathrm{O}, 684=702-\mathrm{H}_{2} \mathrm{O}\right.$, $666=684-\mathrm{H}_{2} \mathrm{O}, 648=666-\mathrm{H}_{2} \mathrm{O}, 630=648-\mathrm{H}_{2} \mathrm{O}, 612=630-\mathrm{H}_{2} \mathrm{O}$.

These results are confirmed by the mass spectrum of perhydro-flavomycoin, too (Fig. 7). The parent peak at $\mathrm{m} / \mathrm{e} 729$ arised from fragmentation of a $\mathrm{H}$ atom, so that the mass number of the molecular ion is 730 . In comparison with the molecule peak of flavomycoin this means an uptake of 5 moles hydrogen per molecule which is 
Fig. 6. Mass spectrum of flavomycoin (negative ion spectrum).

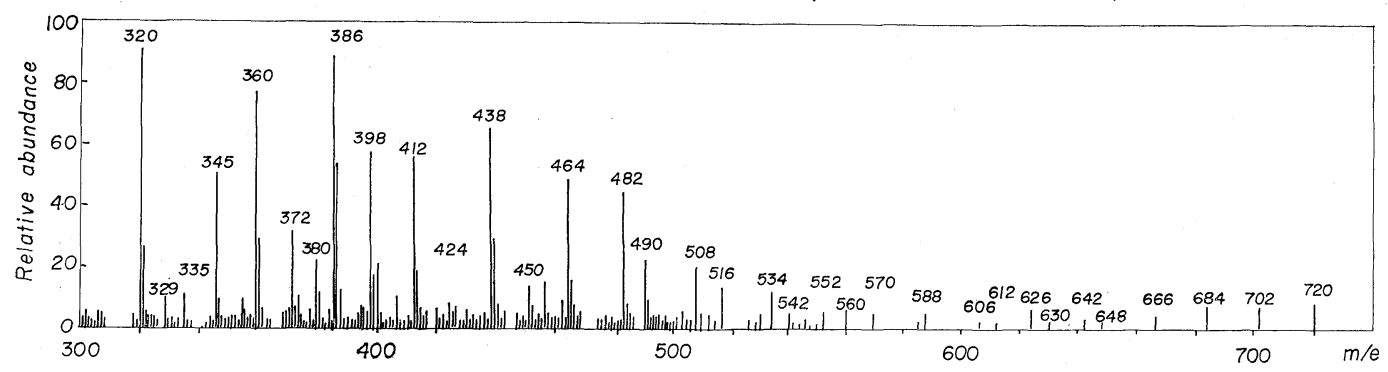

Fig. 7. Mass spectrum of perhydro-flavomycoin (negative ion spectrum).

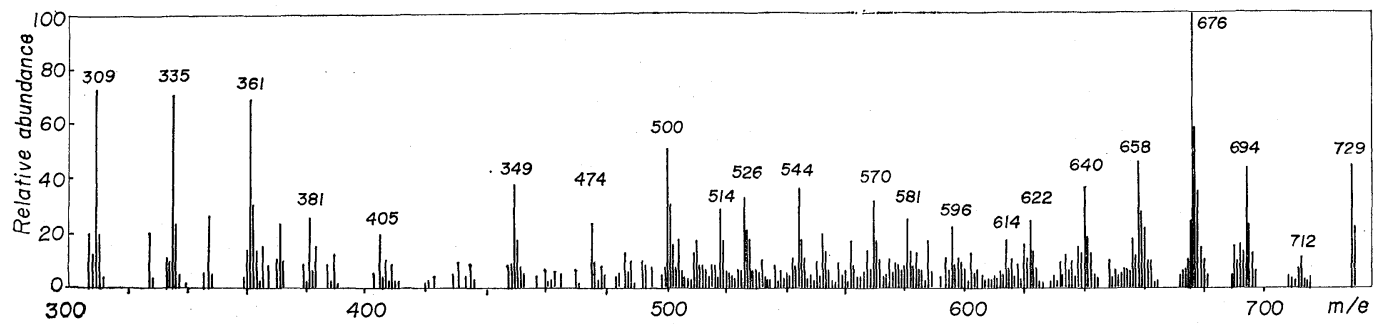

corresponding to the values obtained by catalytic hydrogenation. Furthermore the cleavage of 6 mole $\mathrm{H}_{2} \mathrm{O}$ can also be observed $\left(729=\mathrm{M}-1,712=730-\mathrm{H}_{2} \mathrm{O}, 694=712-\mathrm{H}_{2} \mathrm{O}\right.$, $\left.676=694-\mathrm{H}_{2} \mathrm{O}, 658=676-\mathrm{H}_{2} \mathrm{O}, 640=658-\mathrm{H}_{2} \mathrm{O}, 622=640-\mathrm{H}_{2} \mathrm{O}\right)$.

Comparing the mass numbers in the spectra of both compounds it is remarkable that the difference of 10 mass units appears at the molecular peaks as well as at the most of the following peaks. The results of the mass spectrometry and the quantitative elementary analysis indicated the chemical molecular weight of flavomycoin to be 721 and the molecular formula to be $\mathrm{C}_{41} \mathrm{H}_{68} \mathrm{O}_{10}$.

A further proof for the size of the molecule afforded the degradation to the parent hydrocarbon according to COPE et al. ${ }^{5)}$ Flavomycoin was hydrogenated and the perhydro-flavomycoin reduced with lithium aluminum hydride in refluxing tetrahydrofuran to a polyol which was further treated with red phosphorus in refluxing $48 \%$ hydriodic acid. The hydroxyl-free but iodine-containing product was reduced with lithium aluminum hydride and finally hydrogenated with ADAms catalyst. The chromatographic purification of the hydrocarbon fraction on alumina yielded a colorless oil in an overall yield of $5 \%$. Its infrared spectrum was characteristic of a saturated hydrocarbon and its molecular weight was 576 as determined by negative ion mass spectrometry. Thus the molecular formula of the hydrocarbon is $\mathrm{C}_{41} \mathrm{H}_{84}$. This exactly confirms the former results of molecular weight determination.

\section{Other Reactions}

Flavomycoin was hydrogenated in glacial acetic acid with a platinum catalyst at atmospheric pressure. The uptake of hydrogen was five moles based on a molecular weight of 721. Perhydro-flavomycoin is a colorless substance without biological activity and shows only end absorption in the ultraviolet region. It can be obtained as needles by recrystallization from methanol-water mixtures. The infrared spectrum 
is given in Fig. 3.

Perhydro-flavomycoin was acetylated using acetic anhydride and pyridine at room temperature. The product purified by chromatography showed an acetyl content of 28.9 $\%$ corresponding to seven hydroxyl groups. The infrared spectrum of the acetate and the test according to ZeRewitinofF, however, suggest that a further hydroxyl group is present which cannot be acetylated. The presence of vicinal hydroxyl groups can be excluded because at the quantitative periodate oxidation of flavomycoin and perhydroflavomycoin respectively less than 0.1 mole periodate was consumed.

Quantitative saponification of perhydroflavomycoin required long refluxing in $3 \%$ aqueous alcoholic potassium hydroxide. It consumed 0.95 mole alkali. During saponification no volatile product could be detected by 3,5-dinitrobenzoyl-chloride. Therefore, short chain alcohol as ester component can be excluded. The ZeISEL test was negative, too. The results and the proved size of the

Table 1. Comparison of physico- chemical properties of flavomycoin, flavofungin and mycoticin

\begin{tabular}{|c|c|c|c|}
\hline & Flavomycoin & Flavofungin & Mycoticin \\
\hline $\begin{array}{l}\text { UV-ab- } \\
\text { sorption } \\
\text { maxima }\end{array}$ & $\begin{array}{lll}263 \mathrm{~nm} & \left(\mathrm{E}_{1 \mathrm{~cm}}^{1 \%}\right. & 150) \\
363 \mathrm{~nm} & \left(\mathrm{E}_{1 \mathrm{~cm}}^{1 \%}\right. & 860)\end{array}$ & $\begin{array}{lll}263 \mathrm{~nm} & \left(\mathrm{E}_{1 \mathrm{~cm}}^{1 \%}\right. & 126) \\
366 \mathrm{~nm} & \left(\mathrm{E}_{1 \mathrm{~cm}}^{1 \%}\right. & 869)\end{array}$ & $\begin{array}{lll}262 \mathrm{~nm} & \left(\mathrm{E}_{1 \% \mathrm{~m}}^{1 \%}\right. & 79) \\
364 \mathrm{~nm} & \left(\mathrm{E}_{\mathrm{Icm}}^{1 \%}\right. & 948)\end{array}$ \\
\hline $\begin{array}{l}\text { IR-ab- } \\
\text { sorption, } \\
\text { charact. } \\
\text { band }\end{array}$ & $1100 \mathrm{~cm}^{-1}$ & $1130 \mathrm{~cm}^{-1}$ & $1130 \mathrm{~cm}^{-1}$ \\
\hline $\begin{array}{l}\text { Specific } \\
\text { rotation } \\
{[\alpha]^{D}}\end{array}$ & $\begin{array}{l}-4^{\circ}(4, \text { pyridine }) \\
-45^{\circ}(1, \text { dioxane }) \\
-16^{\circ}(1, \text { methanol })\end{array}$ & $\begin{array}{l}-93^{\circ} \text { ( } 4 \text {, pyridine) } \\
-76^{\circ} \text { ( } 0.2, \text { metha- } \\
\text { nol })\end{array}$ & $+63^{\circ}(0.4$, dioxane $)$ \\
\hline $\begin{array}{l}\text { Melting } \\
\text { point }\end{array}$ & $161 \sim 163^{\circ}$ (dec.) & $210^{\circ}$ (dec.) & $221 \sim 222^{\circ}$ \\
\hline $\begin{array}{l}\mathrm{H}_{2-}^{-} \\
\text {uptake }\end{array}$ & 5 moles & 6 moles & 6 moles \\
\hline $\begin{array}{l}\text { Acetyla- } \\
\text { tion }\end{array}$ & heptaacetate & octaacetate & octaacetate \\
\hline $\begin{array}{l}\text { Deace- } \\
\text { tylation }\end{array}$ & impossible & possible & possible \\
\hline $\mathrm{C}-\mathrm{CH}_{3}$ & 3 & $3 \sim 4$ & $3 \sim 4$ \\
\hline $\begin{array}{l}\text { Mol. } \\
\text { weight }\end{array}$ & 721 & $\begin{array}{ll}\text { A } & 650 \\
\text { B } & 664\end{array}$ & $\begin{array}{ll}\text { A } & 650 \\
\text { B } & 664\end{array}$ \\
\hline Formula & $\mathrm{C}_{41} \mathrm{H}_{68} \mathrm{O}_{10}$ & $\begin{array}{ll}\text { A } & \mathrm{C}_{36} \mathrm{H}_{58} \mathrm{O}_{10} \\
\mathrm{~B} & \mathrm{C}_{37} \mathrm{H}_{60} \mathrm{O}_{10}\end{array}$ & $\begin{array}{ll}\mathrm{A} & \mathrm{C}_{36} \mathrm{H}_{58} \mathrm{O}_{10} \\
\mathrm{~B} & \mathrm{C}_{37} \mathrm{H}_{60} \mathrm{O}_{10}\end{array}$ \\
\hline
\end{tabular}

Fig. 8. Comparison of flavomycoin and flavofungin in infrared spectrum (finger print region).
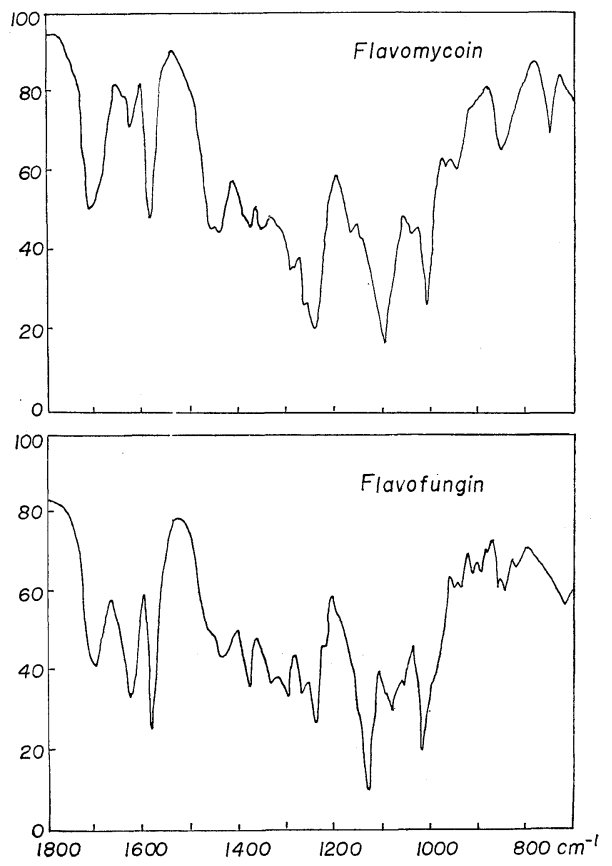

Fig. 9. Comparative papergram of flavomycoin with flavofungin.

Solvent system : chloroform - tetrahydrofuran - formamide (50: $50: 5)$

Paper : Schleicher \& Schüll $2043 \mathrm{~b}, 11 \times 28 \mathrm{~cm}$, ascending, 2.5 hours, $7^{\circ} \mathrm{C}$.

Test organism : Penicillium notatum $\mathrm{P} 36$

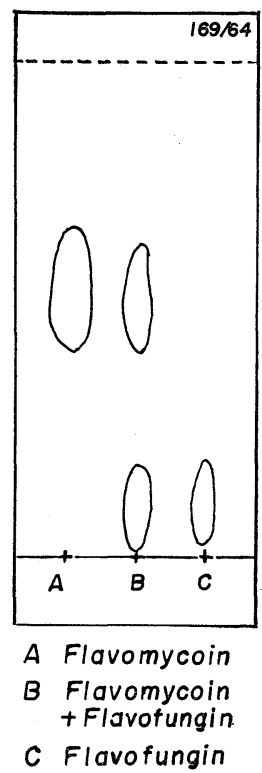


parent hydrocarbon point to a lactone group in flavomycoin.

\section{Comparison of Flavomycoin with Related Antibiotics}

Flavomycoin was compared with the antifungal antibiotics mycoticin ${ }^{6)}$ and flavofungin ${ }^{7,8)}$ which show similar ultraviolet spectra (Table 1). Flavomycoin may be distinguished from flavofungin and mycoticin by its optical rotation, the infrared absorption, the melting point, the uptake of hydrogen, the molecular weight and the impossibility of reconverting the flavomycoin acetate to the original antibiotic by alkaline hydrolysis. The characteristic difference between flavomycoin and flavofungin in the infrared absorption at 1100 $\mathrm{cm}^{-1}$ and $1130 \mathrm{~cm}^{-1}$ respectively is shown in Fig. 8. The complete infrared spectrum of mycoticin is not published up to now. According to BogNAR et al. ${ }^{7)}$ flavofungin and mycoticin are very similar substances. Both antibiotics are mixtures of the same two compounds in different proportions. A direct comparison of flavomycoin and flavofungin using paper chro-

Table 2. Paper chromatography of flavomycoin and flavofungin, $\mathrm{Rf}$ values in different solvent systems

\begin{tabular}{|c|c|c|c|}
\hline \multirow{2}{*}{\multicolumn{2}{|c|}{ Solvent system }} & \multicolumn{2}{|c|}{ Rf values } \\
\hline & & $\begin{array}{l}\text { Flavo- } \\
\text { mycoin }\end{array}$ & $\begin{array}{l}\text { Flavo- } \\
\text { fungin }\end{array}$ \\
\hline I. & $\begin{array}{l}\text { Methanol - water-ammonia } \\
\qquad(80: 16: 4)\end{array}$ & 0.90 & 0.79 \\
\hline II. & $\begin{array}{l}\text { n-Butanol - methanol - water } \\
(4: 1: 2)\end{array}$ & 0.88 & 0.85 \\
\hline III. & $\begin{array}{r}n \text {-Propanol - acetic acid - water } \\
(60: 4: 4)\end{array}$ & 0.94 & 0.95 \\
\hline IV. & $\begin{array}{l}\text { Dimethylformamide - water } \\
\qquad(50: 50)\end{array}$ & 0.77 & 0.72 \\
\hline V. & $\begin{array}{l}\text { Pyridine - butanol - water } \\
\qquad(4: 6: 5)\end{array}$ & 0.86 & 0.89 \\
\hline VI. & $\begin{array}{l}\text { Dimethylformamide - water - } \\
\text { glacial acetic acid }(50: 45: 5)\end{array}$ & 0.84 & 0.81 \\
\hline VII. & $\begin{array}{l}\text { Chloroform - tetrahydrofuran- } \\
\text { formamide } \\
(50: 50: 5)\end{array}$ & 0.55 & 0.12 \\
\hline VIII. & $\begin{array}{l}\text { Chloroform - methylethylketone - } \\
\text { tetrahydrofuran - formamide } \\
\qquad(60: 20: 20: 4)\end{array}$ & 0.42 & 0.01 \\
\hline IX. & $\begin{array}{l}\text { Chloroform - methylethylketone - } \\
\text { formamide } \\
(66: 33: 4)\end{array}$ & 0.33 & 0.02 \\
\hline $\mathrm{X}$. & $\begin{array}{l}\text { Benzene-methylethylketone } \\
(50: 50 \text {, formamide-saturated) }\end{array}$ & 0.69 & 0.45 \\
\hline XI. & $\begin{array}{l}\text { Benzene-dioxane } \\
\text { (50:50, formamide-saturated) }\end{array}$ & 0.21 & 0.07 \\
\hline
\end{tabular}
matography is shown in Fig. 9. The $\mathrm{Rf}$ values in different solvent systems are summarized in Table 2.

\section{Conclusions}

By reason of the physico- chemical properties and paper chromatographic investigations, flavomycoin is different from other similar substances. Therefore, it must be considered as a new antibiotic.

\section{Experimental}

Flavomycoin

A sample of the purified antibiotic was crystallized from $80 \%$ methanol as needles, m.p. $161 \sim 163^{\circ} \mathrm{C}$ (dec.). The substance was dried at $22^{\circ} \mathrm{C}(0.1 \mathrm{mmHg})$ and immediately submitted for analysis.

Anal. Calcd. for $\mathrm{C}_{41} \mathrm{H}_{68} \mathrm{O}_{10} \cdot 2 \mathrm{H}_{2} \mathrm{O}:$ C $65.05, \mathrm{H} 9.58, \mathrm{H}_{2} \mathrm{O} 4.75 \%$

$$
\text { Found: } \quad \text { C } 64.49, \quad \mathrm{H} 9.35, \mathrm{H}_{2} \mathrm{O} 4.23 \%
$$

Perhydro-flavomycoin

A solution of $1.075 \mathrm{~g}$ flavomycoin was hydrogenated with $83 \mathrm{mg}$ of platinum oxide in $50 \mathrm{ml}$ of glacial acetic acid for 5 hours at room temperature. The catalyst was removed 
by filtration, the solvent by freeze-drying. Two recrystallizations of the residue from a mixture of methanol - water $(7: 3)$ yielded $880 \mathrm{mg}$ of colorless, fine needles, m.p. $80 \sim 82^{\circ} \mathrm{C}$. $[\alpha]_{\mathrm{D}}^{25}-11^{\circ}$ ( $c 4$, pyridine). For analysis the substance was dried in vacuo $(0.1 \mathrm{mmHg})$ at room temperature over phosphorus pentoxide.

$$
\begin{aligned}
& \text { Anal. Calcd. for } \mathrm{C}_{41} \mathrm{H}_{78} \mathrm{O}_{10} \cdot 2 \mathrm{H}_{2} \mathrm{O} \text { : C 64.36, } \mathrm{H} \text { 10.54, } \mathrm{H}_{2} \mathrm{O} 4.7 \% \\
& \text { Found : } \\
& \text { C } 64.79, \mathrm{H} 10.20, \quad \mathrm{H}_{2} \mathrm{O} 3.9 \sim 4.5 \%
\end{aligned}
$$

Acetylation of perhydro-flavomycoin

Perhydro-flavomycoin $(500 \mathrm{mg}$ ) was dissolved in $15 \mathrm{ml}$ of acetic anhydride and $10 \mathrm{ml}$ of pyridine. The mixture was allowed to stand for 48 hours at room temperature and then concentrated to $10 \mathrm{ml}$ in vacuo. After $150 \mathrm{ml}$ of ice-water was added, the mixture was allowed to stand overnight at room temperature and then extracted with chloroform three times. The combined chloroform extracts were washed with water, dried with anhydrous sodium sulfate, concentrated to about $5 \mathrm{ml}$, and chromatographed on alumina (neutral, activity II). The chloroform eluate was evaporated under reduced pressure to yield $190 \mathrm{mg}$ of colorless glass, m.p. $60 \sim 62^{\circ} \mathrm{C}$.

$$
\begin{aligned}
& \text { Anal. Calcd. for } \mathrm{C}_{55} \mathrm{H}_{92} \mathrm{O}_{17} \text { : C 64.43, H 9.04, } 7 \times \mathrm{COCH}_{3} 29.35 \% \\
& \text { Found: } \quad \mathrm{C} 64.18, \mathrm{H} 8.96 \quad \mathrm{COCH}_{3} 28.95 \%
\end{aligned}
$$

Quantitative saponification of perhydro-flavomycoin

Perhydro-flavomycoin (0.206 g) was dissolved in $20 \mathrm{ml}$ of $70 \%$ ethanol and $20 \mathrm{ml}$ of $1 \mathrm{~N}$ ethanolic $\mathrm{KOH}$. After refluxing for 4 hours the alkaline solution was titrated with $1 \mathrm{~N} \mathrm{HCl}$ using a potentiometer. The consumption of $2.69 \mathrm{ml} 1 \mathrm{~N} \mathrm{HCl}$ corresponds to 0.95 mole $\mathrm{KOH}$ per mole perhydro-flavomycoin.

\section{Conversion of perhydro-flavomycoin to parent hydrocarbon}

A solution of $8.0 \mathrm{~g}$ of perhydro-flavomycoin in $400 \mathrm{ml}$ of tetrahydrofuran was heated under reflux for 40 hours with an excess of lithium aluminum hydride. The unchanged hydride was destroyed with ethyl acetate and the mixture evaporated to dryness. The inorganic material was dissolved in dilute sulfuric acid and the polyol extracted with $n$-butanol. The combined extracts were washed with water and the butanol was removed in vacuo. The oily residue was dissolved in a little $t$-butanol and freeze dried to yield $7.1 \mathrm{~g}$ of white amorphous powder.

Seven grams of polyol were dissolved in $100 \mathrm{ml}$ of glacial acetic acid and added to a refluxing suspension of $420 \mathrm{ml}$ of $48 \%$ hydriodic acid and $10 \mathrm{~g}$ red phosphorus. After 24 hours $170 \mathrm{ml}$ hydriodic acid were removed by distillation, $350 \mathrm{ml}$ of water added and the mixture was extracted with $100 \mathrm{ml}$ of chloroform thrice. The extracts were washed with $2 \%$ sodium thiosulfate solution, then with water, and dried over anhydrous sodium sulfate. Removal of solvent gave an oil $(3.25 \mathrm{~g})$ which was dissolved in tetrahydrofuran and refluxed for 10 hours with $3 \mathrm{~g}$ of lithium aluminum hydride. The unchanged hydride was destroyed with ethyl acetate. After evaporation of the solvent, the inorganic material was dissolved in $10 \%$ sulfuric acid and organic material extracted with hexane. The hexane solution, after being washed with $5 \%$ sodium carbonate solution and dried over sodium carbonate, was concentrated and hydrogenated using platinum oxide as catalyst. The catalyst was separated and the concentrated solution chromatographed on a column of neutral alumina (activity II). The first fractions eluted with hexane were combined and yielded $390 \mathrm{mg}$ of hydrocarbon.

\section{Paper chromatography of flavomycoin}

Method: Ascending chromatography on Schleicher and Schüll 2043b paper. Temperature: $7^{\circ} \mathrm{C}$. For the solvent systems VII XI (Table 2) the paper sheets were impregnated with $20 \%$ solution of formamide in acetone for 5 minutes. Then the sheets were pressed between filter paper and after air drying the solutions of antibiotics were applied. 
Acknowledgements

The authors wish to express their thanks to Dr. R. TümmLER, Research Institute Manfred von Ardenne, Dresden, for measurements of mass spectra and Dr. J. URI, formerly at the Department of Pharmacology, University Medical School, Debrecen (Hungary), for his kind gift of flavofungin.

\section{Reference}

1) Schlegel, R.; H. Thrum, G. Bradler \& R. Fügner: Flavomycoin, ein neues Polyenantibiotikum: Produktion, Isolierung und Eigenschaften. Ztschr. Allg. Mikrobiologie, in preparation

2) Schlegel, R. \& H. Thrum: Flavomycoin, ein neues antifungales Polyenantibiotikum. Experientia $24: 11 \sim 12,1968$

3) Ardenne, M. v.; K. Steinfelder, R. Tümmler \& K. Schreiber: Molekül-Massenspektrographie von Naturstoffen. Steroide. Experientia $19: 178 \sim 180,1963$

4) Ardenne, M. v.; R. Tümmler, Ek. Weiss \& T. Reichstein: Massenspektroskopie bei Cardenoliden und anderen stark hydroxylierten Steroiden. Helv. Chim. Acta $47: 1032 \sim 1038,1964$

5) Cope, A. C.; R. K. Bly, E. P. Burrows, O. J. Ceder, E. Ciganek, B. T. Gillis, R. F. Porter \& A. E. Johnson: Fungichromin: Complete structure and absolute configuration at $\mathrm{C}_{26}$ and $\mathrm{C}_{27}$. J. Am. Chem. Soc. $84: 2170 \sim 2178,1962$

6) Wasserman, H. H.; J. E. Van Verth, D. J. McCaustland, I. J. Borowitz \& B. Kamber: The mycoticins, polyene macrolides from Streptomyces ruber. J. Am. Chem. Soc. 89: 1535 1536, 1967

7) Bognár, R.; B. O. Brown, W.J.S. Lockley, S. Makleit, T. P. Toube, B.C.L. Weedon \& K. ZsUPAN: The structure of flavofungin. Tetrahedron Letters $1970: 471 \sim 474,1970$

8) Bogná, R.; I. Farkas, S. Makleit, M. Rakosi, J. Soltesz, L. Somogyi \& K. Zsupan: Chemical properties of flavofungin. Antibiotiki $10: 1059 \sim 1066,1965$ 